\title{
Alrededor de "María"
}

\section{(Eco de una controversia)}

$\mathrm{E}^{\mathrm{N} T R E}$ los asuntos de última hora que la prensa de Colombia trae, leo la controversia que se ha suscitado, sobre la paternidad de la novela María.

Visité una vez, en compañia de un profesor norteamericano, dotado de muy noble espíritu, la Academia Naval de Annápolis. Bajamos al sarcófago que guarda los restos de Paul Jones, el fundador de la marina de este gran país, y cuando salíamos del sótano que guarda, bajo simbólico mármol, sus restos, el profesor, con la ingenuidad del yanqui de buena fe, me dijo: "Lo más probable es que no sean esos los restos de Paul Jones, pero alli está la idea..." Me impresionó el concepto, esa devoción a la idea, del patriota sincero, inteligente y generoso y pensé, en seguida, en lo que pasa allá entre nosotros.

En Colombia, siempre estamos de controversias. Somos un país de iconoclastas. Lo único que allá crece son los políticos, que se multiplican como hongos. La política es la mejor profesión, $y$, por lo mismo, la más popular de las profesiones. El pais crece también, pero nadie podrá detener el crecimiento de un árbol, de un niño. $Y$ hasta los políticos son iconoclastas; su obra es destructora. Sin ellos el pais llevaría una vida más tranquila.

Allá todo se destruye: las históricas murallas, las selvas que enriquecen el caudal de los ríos, las aves, la vida silvestre, hasta la reputación de buenos funcionarios que han sintetizado el sentimiento y el honor nacionales. En otros pueblos, se crean leyendas para fortalecer el espíritu nacional. Nosotros destruimos realidades, pero 
al politico audaz se le halaga, por conveniencias personales momentáneas. El espiritu nacional no cuenta.

Todo lo que vale, lo hemos discutido en Colombia. No nos detenemos ni ante las más nobles y heroicas tradiciones. Que Bolívar no estuvo en Boyacá; que Ricaurte no se sacrificớ en San Mateo, etcétera. ¿ Nada escapa a nuestró espiritu destructivo!

La nueva controversia sobre el autor de Maria, afortunadamente, es esta vez un asunto de familia.

Isaacs fué un gran sentimental; un gran lírico, amargado, como Silva, por la estrechez de su medio; por las pasiones bajas y por la envidia, planta frondosa entre gentes mediocres, pobres y pequeñas.

Conocí y traté en mi adolescencia a don Alcides Isaacs, hermano del autor de María. Era yo un muchacho entusiasta. Los héroes y las glorias nacionales me seducían. Un hermano del autor de la novela inmortal, era para mí una reliquia veneranda. Así me acerqué a don Alcides, un buen señor, un caballero afable, que supo complacer mis entusiasmos juveniles.

Entonces escribía yo, y esto era en los comienzos de la guerra de los mil días, correspondencias para el diario mexicano El Tiempo, grañ amigo de Colombia, dirigido por el licenciado don Victoriano Agüeros, muerto ya hace muchos años, y fanático admirador de la obra literaria de Isaacs.

Don Alcides, de un tipo inglés, más que español o hebreo, lo cual prueba que por el lado de su padre había en los Isaacs mezcla de las dos razas, gozaba con mis entusiasmos de niño y muy inefablemente con las repercusiones de la obra literaria de su amado hermano.

Para complacer los deseos del editor del diario mexicano, me dió él una poesía inédita de don Jorge. Tódo eso se publicó en México en una edición dominical, sección especial, del diario ya referido, en julio de 1902.

La poesia la conservaba sólo en su memoria don Alcides, quien me la dictó. Creo que nunca ha sido publicada en Colombia. La compuso el autor de María en la muerte de la esposa de su hermano don Carlos, fallecida en Cali en 1861, según Gustavo Arboleda (Dic- 
cionario biográfico), y según otras fuentes, en junio de 1889. Es una muy tierna elegía. Dice así:

Cubrid de niveas y fragantes flores

La tumba de la esposa inmaculada:

Dícha fugaz, desvelos $y$ dolores

Halló de la existencia en la jornada.

No turbéis con lamentos y clamores,

Seres que amó, su fúnebre morada.

Sollozad en silencio, que despierta;

Se ba dormido y descansa; no está muerta.

Por lo que yo recuerdo, siempre me pareció don Alcides Isaacs orgulloso en extremo de la gloria literaria de su hermano. No es posible que haya podido hacer ni en la senectud de los años alguna declaración contradictoria a la paternidad de la obra, ante sus hijos. Si alguna duda hubiera al respecto queda disipada completamente con la declaración muy perentoria que hizo en carta a la prensa don Santiago Isaacs, el hijo menor de don Alcides y que se precia de haber sido el fiel compañero y confidente de su padre, en sus últimos días. Quién sabe qué confusión de recuerdos y de ideas hubo en la mente de su hermano Antonio, cuando hizo las declaraciones que le atribuyó un periodista, o no sé si el periodista tergiversó los hechos.

En cuanto a la autenticidad de los personajes y paisajes de Maria, la discusión no vale un comino. Esto también lo hemos discutido. Todo es real, menos la figura central, María; pero esa figura estaba en el corazón, en el alma del poeta. Es la figura que todos llevamos en la edad primera.

El paisaje es real. Tan real, que yo, nativo del Valle del Cauca, no me he atrevido a releer la novela para no sentirme triste, para no sentirme homesick en esta larga ausencia. Los personajes y costumbres, son todos reales. El hijo del Señor de M., el rival de Efraín, el buen mozo de tás patillas, que punteando la guitarra cantó aquellas estrofas que empiezan: :

El ronco són de la guérrera trompa

Llamó tal vez a la sangrienta lid

era, según tradiciones de familia, el más tarde doctor Carlos Martínez, dueños ellos de haciendas aledañas, como "El Alisal", "I a Concepción"; etc. 
Maria misma es el único misterio. Cuantas versiones y conjeturas se han dado a la estampa, han resultado incomprobables. Rivera y Garrido, aquel otro delicado literato del Valle, encontró a casi todos los personajes de la novela, incluso al negró Juan Angel, que era de sangre real africana.

María fué una fantasía, tal vez el primer amor del poeta. Pudo haber sido la que más tarde fué su esposa o pudo haber sido alguna otra adorable criatura de las haciendas vecinas. En cierta edad, las mujeres en la flor de sus primeros años han sido siempre causa fugaz de los más profundos ensueños y sentimientos.

En una revista de Buenos Aires, se publicó hace muchos años la leyenda de que María vivía en Bogotá y que era una prestante dama de esa sociedad.

La aludida era doña Mercedes Holguín de Uribe y nada de particular tendría que esa dama hubiera sido el sueño del joven poeta en los dias en que concibió la novela.

Los Holguín eran dueños de la hacienda de "El Asombro"; no muy distante de "El Paraíso", hacienda del padre de Isaacs, que la había comprado de uno de los Martínez, de los ricos terratenientes del Valle en esos días en que familias opulentas y patriotas, por lo mismo desinteresadas, contaban en los destinos del país.

Recién llegado yo a Bogotá, en 1904, tuve el honor de conocer a doña Mercedes, en su residencia de la "Calle de Paláu". iQué gran dama aquélla! Me recibió, por lazos de familia con mi padre, con una gentileza sin igual, que entonces yo adivinaba, pero que no apreciaba en todo su valor. No volvi a verla, cosa que siempre he deplorado. Murió no muchos meses después de mi visita.

Ya en aquella época me interesaban las intrigas alrededor de María. Yo había leído lo que en Buenos Aires se escribió sobre ella, y al preguntar a doña Mercedes, me dijo con alegre sonrisa.y gran discreción: "Algún día hablaremos :de eso". ¿Fué doña Mercedes en su bella y florida juventud una de aquellas ilusiones que flotaron en la temprana juventud del poeta, en medio de aquel paisaje ensoñador?

Sobre la aparición de Mariá hay una información concluyente en el artículo que publicó Luciano Rivera y Garrido. Este escritor cuenta que Isaacs decía a uno de sus intimos amigos en vísperas 
de la aparición de su obra: "Yo he sentido la emoción de mi libro. ¿La sentirá el público?"

Quien escribió aquellas páginas tan llenas de ternura, que se titulan "Leyendo a María", es el autor inconfundible de la novela inmortal. "Páginas queridas, demasiado queridas quizá! Mis ojos han vuelto a llorar sobre ellas! Las altas horas de la noche me han sorprendido muchas veces con la frente apoyada sobre estas últimas, desalentado, para trazar algunos renglones más.

"A lo menos, en las salvajes riberas del Dagua, el bramido de sus corrientes arrastrándose a los pies de mi choza, iluminada en medio de las tinieblas del desierto, me avisaba que él velaba conmigo!"'

- Estas palabras enternecedoras prueban que Isaacs, en las páginas de su novela, habia vertido todo el sentimiento de un amor temprano. En su poema "Ten piedad de mi" parece advertirse que se trata de un amor, de una ilusión perdida, de un vago ensueño, que tantos hemos llorado. No resisto al deseo de transcribir aquí el tan conocido poema, hermano espiritual de la novela y de la página "Leyendo a Maria":

Señor! Si en sus mirảdas encendiste este fuego inmortal que me devora, $y$ en su boca fragante $y$ seductora sonrisas de tus ángeles pusiste:

Si de tez de' azucena la vestiste y negros bucles; si su voz canora, de los sueños de mi alma arrulladora, ni a las palmeras de tus selvas diste

Perdona el gran dolor de mi agonía y déjame buscar también olvido en las tinieblas de la tumba fría.

Olvidarla en la tierra no be podido. Cómo esperar podré si ya no es mía? Cómo vivir, Señor, si la he perdido?

Todo este proceso sentimental parece bien claro.

Isaacs cantó sus primeras emociones y cantó el imperdonable paisaje nativo. Es pues un poeta nacional; un positivo poeta caucano. 
Se han empeñado en judaizar a Isaacs y no puede haber un temperamento más definitivamente colombiano. Fué hombre ardoroso, como hijo del trópico. Tomó parte en las luchas armadas de Colombia $y$ en las luchas políticas, con el amor y valentía de un hombre de raza española. En lo sentimental, hemos probado en otro trabajo, que se publicó hace años en una edición dominical de El Tiempo, su ascendencia napolitana (Scarpetta Roo), ascendencia común a otras inteligencias prestantes de Colombia. En él, pues, se dieron la mano influencias raciales muy diversas; y como él, otros muchos poetas caucanos que no tenían nada de hebreos, han cantado el paisaje nativo.

Ahora también, otro escritor destructor lanza la idea de que María simboliza a la muchacha hebrea y no a las pudibundas y castas muchachas del Cauca de aquellos días. Al fin nada va a quedarnos del poeta y su obra. i $Y$ nosotros, que siempre hemos visto allá en el Cauca, una Maria en cada novia de los primeros años!

"Vuela tú, entristecida alma mia" -dice el poeta desde la soledad de su choza del Dagua-. "Cruza las pampas, salva las cumbres que me separan del Valle Natal. Cuán bello debe estar ahora entoldado por las gasas azules de la noche.

"Ciérnete sobre mis montañas: vaga otra vez bajo esos bosques que me niegan sus sombras!..."

IQué sublime invocación ésta del poeta! Viene ella a los labios de uno; sale del fondo del corazón. $Y$ este hombre tan sentimental, de impulsos generosos, que se vió envuelto en la metralla de los odios políticos, sintió también la amargura de la hostilidad mezquina dé gentes mediocres!

Dejemos en paz a Isaacs y su obra. Su gloria es nuestra gloria. Por encima de cuantas necedades se han dicho, ha sido él un auténtico representativo de nuestra raza y de nuestro pueblo.

EnRigue Naranjo M, Boston, Mass. 